\title{
Intellectual Property Education - Thinking outside the Box meets Colouring within the Lines
}

\author{
Author 1
}

Author 2

\begin{abstract}
A basic understanding of intellectual property (IP) is essential for practice as a professional engineer and/or designer to ensure commercial success. Engaging students in a 'real-life' scenario or problem is one of the most effective methods of doing this. As they must first understand the problem, then seek knowledge to solve the problem, which ensures they develop their skills along the way. This paper concerns how intellectual property rights education is addressed in the HIGHER education of both lawyers and designers/engineers. It is written jointly, from the perspective of both design/engineering and law education and focuses on the pedagogical issues that are different or shared.
\end{abstract}

Keywords: Intellectual Property; student centred learning; collaborative learning; product design; law education; design education

\section{$1 \quad$ Introduction}

"I hear and I forget. I see and I remember. I do and I understand." (Confucius c 551 - 479 BC)

This paper reports on an example of collaborative student centred learning activity between BA/BSc Product Design (PD) and LLB Law (Intellectual Property Practice option) (LLB) final year students at Bournemouth University (BU). The final year product design students are required to design and produce a working prototype of a marketable product. The LLB students advise on the intellectual property aspects of the design. This learning activity has been ongoing for a number of years. The activity has proved to be an extremely valuable learning experience for both sets of students, providing simulation of real life for both designers and IP lawyers and bridging the academic/industrial interface.

The pedagogy of law education for lawyers is well established. However, legal education involves more than educating legal professionals. Law teachers should be recognised as 'professionals' themselves instead of being considered 'purely legal' educators. (Burridge et al, 2002) Legal education for the public at large is growing in such a manner that "individuals as citizens and consumers are in a position to enforce their rights and discharge their responsibilities, and to use legal services to their advantage." (Brooker, 2004) This growth will have a double impact on law schools, increasing the number of law school academics re-examining how they facilitate learning law as well as increasing the opportunities for interdisciplinary collaborative legal research like this paper. Law schools are looking to design intellectual property programmes that are relevant to business, the creative industries and science and technology. At the same time, faculties of diverse disciplines including business, chemistry, engineering, bioscience, medicine, arts and humanities are themselves beginning to appreciate that intellectual property should feature on their curricula. (Soetendorp, 2006) Some schools are beginning to develop intellectual property programmes, with or without law school involvement. 


\section{$2 \quad$ Literature Review}

\subsection{IP Education for Lawyers}

Roach and Soetendorp (2008) report that a number of IP organizations around the world, such as the World Intellectual Property Organization; The Canadian Intellectual Property Office and the European Patent Office (EPO) consider IP education to be important, to the extent that the EPO run workshops specifically for universities to disseminate knowledge about IP. The Treasury Review of Intellectual Property (Gower, 2006) unfortunately chose to focus on the negative aspects of IP education, that is, protection from fraudulent copying but did not emphasize the positive aspects related to the relationship of IP to commercial success.

Booton and Prime (2001) surveyed IP teaching in UK LLB programmes. They found 'the deep moral, philosophic and ethical issues to which it [a study of IP law] gives rise.' Their research focussed on how the demands of the legal profession influenced the way in which IP law was taught. IP legal education seeks to encourage students to 'think' like a lawyer. How? The development of skills of critical analysis is probably the most important aspect of university education - there is no doubt that all graduates should be equipped with the necessary skills to solve complex problems, whether the problems in questions are economics, business decisions or politics. It could be said that in the context of legal education, students are encouraged to 'think' like a lawyer by developing the ability of spotting and analysing issues in order to tackle a problem, identify relevant facts and give appropriate advice after considering possible arguments from both sides. (Allen, 2006) The essence of it, as Cownie (2004) aptly put it, is that "law is an argument not a statement, it is to be debated and discussed".

There is a need to promote awareness and knowledge of intellectual property issues. "To accomplish effective social regulation one must ensure that any progress mirrors the interests of an informed society and that the lawmaking process can be conceived as an effective cycle." (Schiavetta, 2001) Education about intellectual property is important to give practitioners the knowledge and skills that they need to help creators of intellectual creations manage their affairs, to allow them to avoid legal disputes in their transactions with others, or to deal with disputes appropriately if they cannot be avoided. Many non-law students are either unaware of, or struggle to understand, their legal rights and obligations, especially among undergraduates on, and recent graduates of engineering/design courses in the UK. (Roach and Soetendorp, 2008) The Engineering Council UK (ECUK) has acknowledged that an understanding of intellectual property rights is essential in order to practice effectively as a professional engineer and/or designer. Now IP students can help engineering students be more efficient users of the justice system.

\subsection{Role of IP for Designers/Engineers}

The Engineering Council UK (ECUK) requires an understanding of intellectual property rights to practice as a professional engineer and/or designer. Indeed, ECUK make this explicit in UK-SPEC (2008), section A2, "Engage in creative and innovative development of engineering technology and continuous improvement systems.....secure the necessary intellectual property rights." However, as Roach and Soetendorp (2008, p.3) report, there are both low levels of awareness of IP and a number of perceived barriers to the incorporation of IP into engineering/design curriculum. Their report focuses on undergraduates, and recent graduates of engineering/design courses in the UK. They report the barriers as being: 
- Engineering academics' belief that IP content is not as important as other engineering content;

- The engineering curriculum is already overcrowded and could not support any new subjects;

- No established pedagogy for creating well planned, integrated, sequenced and cumulative learning experiences to integrate relevant material form other disciplines into the core engineering curricula.

There are a number of indications of the need to set the traditional engineering curricula in a wider context that includes the increasing importance of enterprise (Outram, G., Stevens, C. and Culley, S, 2007; Wood and Duffy, 2008) as well as IP. This is particularly the case for engineers entering small and medium size enterprises, as highlighted in a study undertaken for the DTI and UK Intellectual Property Office (UK IPO) (Pitkethly, 2006). However, IP in an enterprise context is only mentioned in passing, missing the important link between IP and commercialization of ideas and products.

\subsection{Pedagogy of IP Education}

The third of the barriers stated above requires a pedagogy to be established to enable the effective integration of contextual materials such as IP, enterprise and commercialization. In order to ensure that students experience deep learning (Race, 2005) full engagement with the subject must occur and that certain types of learning and teaching method work better than others in ensuring this full engagement with the subject. Engaging students in a 'real-life' scenario or problem is one of the most effective methods of doing this is as they must first understand the problem and then seek knowledge to solve the problem, which ensures they develop their skills along the way. "Some say that the most valuable learning experience is from participation in real life situations." (Shiavetta, 2001)

Clinical legal education provides law students with the tools that lay the foundations for their future careers as lawyers. While traditional legal education tends to focus on the theoretical content of the law and to be knowledge-based, clinical legal education goes further and provides law students with the necessary skills for legal practice. It also inculcates values such as the duty of lawyers to become involved in social justice issues in society, and to display professional responsibility while practising law. Many of these skills and values can also be incorporated into the teaching of substantive and procedural law. (McQuoid-Mason, 2006)

Soetendorp (2004) based on Hennessey (1999) reports on a range of approaches that she has adopted to teach IP material to engineering and design students. She lists these as the case method; the problem-solving method; the simulation method; the clinical method and the doctrinal method. While Soetendorp reports that she has tried most of these methods with different groups of students it is the clinical method that is of interest here. This method is based upon the idea, patients, seeking advice from doctors or, more generally, professionals. In a teaching and learning situation the role of patient is undertaken by one group of students and the role of doctor (professional) by another group.

Hence, clinical legal education is so important because of the experiential learning whereby law students gain practical skills and deliver legal advice in a practical environment. During the process students are confronted with real life situations and play the role of lawyers to solve the problems. They do this by interacting with clients or each other to identify and resolve legal issues, and are subjected to critical review by their teachers or peers. Clinical legal education 
enables law students to play an active role in the learning process and to see how the law operates in real life situations (Brayne, Duncan \& Grimes, 1998:1). Clinical legal education programmes usually take the form of 'live client' or 'street law' (legal literacy) type clinics. However at Bournemouth University, these learning methods have been adapted for use when teaching substantive and procedural law in intellectual property.

\section{Project History}

This learning experience has been in operation at Bournemouth University (BU) since academic year 2006/2007, however, iterative changes have been made each time the project has been operated due to the outcomes found during evaluation of the previous cycle. The learning experience uses the clinical method and also involves collaborative student centred learning between Product Design (PD) and LLB Law (Intellectual Property Practice option) LLB final year students at BU in a clinical style. The final year PD students are required to design and produce a working prototype of a marketable, preferably, commercial product. The law students are required to advise on the intellectual property aspects of the design. This advice culminates in a piece of assessed work which takes the form of an Advice Letter, as described below. The number of students varies year upon year but typically involves around 100 students. This provides a real-life scenario, the PD students have very 'real' projects which some of them go on to commercialize. As these students have to manufacture a working prototype they have fully developed designs thus they have both a genuine interest in potentially protecting their IP and a good level of detail and understanding of the design of the product. Therefore, providing the opportunity for LLB students to work with 'real' products that enables them to undertake 'real' searches and offer advice that has the potential to be taken up in 'real-life' by the PD student.

In each year of operation the learning experience has been commenced at a 'Masterclass' that PD and LLB students attend where specialists give presentations. The specialists have included Patent Attorneys, practicing IP Lawyers, individual designers/inventors who have had to defend their own IP as well as representatives from companies who exploit IP to further their business success. In academic year 2007/08 the students were also introduced to the operation of the discussion forums via the VLE and introduced to each other in their respective groups at this event.

Individual PD and LLB students were paired together in the academic year, 2006/07. However, situations arose where one or other party did not fully engage leaving the other student in a difficult, and in terms of assessment, inequitable situation. Thus a change was made in the subsequent year, 2007/08, whereby PD and LLB students were grouped together in groups of $4 / 5$ students, this also had the added advantage of dealing with unequal numbers of PD and LLB students. For the first time in academic year 07/08, both PD and LLB students had assessed elements. The LLB students undertaking the Advice Letter mentioned above, but with the added element that the PD student were required to peer review the advice letter. The PD students were also required produce a chapter of their Final Year Project Reports on Professional Issues centring on an IPR analysis of their product - this element is approx $15 \%$ of their final project report.

Additionally, a difference form of communication was introduced via a virtual learning environment (VLE). The BU VLE - myBU - was used to provide group based discussion forums. A well respected, retired Patent Attorney also offered a prize for the best PD and best LLB student and for the group that worked the most effectively. The third year of operation, 2008/09, saw little fundamental change, with students again working in groups, both sets of students having 
assessed elements and communication taking place ostensibly via myBU. The prize was again offered by the same retired Patent Attorney.

\subsubsection{Advice Letter}

As Roach and Soetendorp report (2008) an assessment methodology has evolved over a number of academic years. It is based around the requirement for the LLB students to construct an advice letter and follows the 'clinical' method discussed above. In simple terms a group of final year undergraduate students on law courses advise a group of final year undergraduate students, conducting projects to design/engineer products, as part of their design/engineering courses. The nature of this advice takes the form of a letter such as that which an IP lawyer might write to a client who is a designer or engineer and who has approached them with a product or engineering solution. In other words there is an expectation that a range of issues are pointed out to the client, such as, what form of IP might be applicable (Patent, Registered Design etc) or whether the design as it stands infringes anybodies' IP (so effective searches must be conducted). Clearly, this requires the lawyer to understand the work being presented to them by the designer/engineer and it requires the designer/engineer to ensure they are both explaining the work fully and getting their questions answered.

Roach and Sopetendorp (2008, p13) quote David Morgan, Enterprise and Education Development Manager with the UK Intellectual Property Office: "I am most impressed by the innovative approach taken...to deliver what is sometimes perceived as a difficult subject to undergraduates, that is a means of conveying to undergraduates some understanding of the key role that IP plays in enabling business to compete successfully in global economies...At the UK IPO we consider engagement with this target audience to be a key element in attaining one of our objectives which is to...ensure they acquire sufficient knowledge and understanding of the key role that IP plays in enabling business to compete successfully in global economies."

\section{$3 \quad$ Methodology}

\subsection{Evaluation Methods}

The evaluation of the 2007/08 operation was conducted by qualitative analysis of the discussion forums, which all academic staff involved had access to, and by analysis of the Peer Review forms, a partial report on this can be found in Humphries-Smith, 2009. The evaluation of 2008/09 operation also analysed the discussion forums and the Peer Review forms. The peer review forms were only completed by PD students who were asked to assess the advice letter on a score of (low) 0-5 (high) which contributed to 5\% of the mark for the assignment. They were asked to respond to the following questions in making this assessment:

- Advice letter - presentation (eg was advice well presented?)

- Advice letter - clarity (eg Are you clear about your needed IP actions? Does the advice letter accurately reflect the previous communications and meetings that you have had?)

- Communication (eg Was this two-way?/Did your questions get answered?)

- Timeliness (eg Did you get replies within a reasonable time frame?/Did you have to chase for results or did the IPP student manage this process well?)

- Meetings (eg did IPP student initialize meetings and conduct them in a professional manner?/Was feedback given after meetings to confirm discussions?)

- Other factors

In 2008/09 the authors also requested that the students provide direct written feedback of the 
learning experience via a qualitative questionnaire. The following questions were asked:

1. Considering the experience of working in a group, what if any, were a) the academic benefits $b$ ) the social benefits?

2. What 'rules' appeared to prevail in the group?

3. Were these rules negotiated - or did they arise spontaneously with given situations?

4. What worked well? What experiences were most helpful in planning and completing the task?

5. What didn't work? Did any particular incident or situation help or hinder your group's functioning?

6. What, if any, 'preparation' did you have for this activity? What role do you think academic staff could/should play in preparing students for collaborative learning?

7. Do you feel that you learnt more as part of this group activity than you would have working on the same activity individually? Yes/No, Please elaborate.

8. Is there anything you would change about your own behaviour or approach in future collaborative learning situations? Yes/No, Please elaborate.

\section{$4 \quad$ Results}

The results presented here are based on the 2007/08 and 2008/09 operation of this learning experience. There were 59 PD students and 46 LLB students who were divided into 23 groups in 2007/08 and 50 PD students and 65 LLB students who were divided into 26 groups in 2008/09. The results presented here compare extracts from the VLE based discussion forums and from the peer review of the advice letters undertaken by PD students from two cohorts. Further a qualitative analysis of feedback about the learning experience obtained from both LLB and PD students is also presented.

\subsection{Peer Review}

PD students were asked to assess the advice letter provided by the LLB students. Table 1 below indicates how many PD students scored the LLB students at each mark in 2007/08 and 2008/09 respectively.

Table 1. Student Marks for Advice Letter

\begin{tabular}{|c|c|c|c|c|c|c|}
\hline AY07/08 & $\begin{array}{l}\text { Score } 0 \\
2\end{array}$ & $\mid \begin{array}{l}\text { Score } 1 \\
0\end{array}$ & $\begin{array}{l}\text { Score } 2 \\
1\end{array}$ & $\begin{array}{l}\text { Score } 3 \\
3\end{array}$ & $\begin{array}{l}\text { Score } 4 \\
24\end{array}$ & $\begin{array}{l}\text { Score } 5 \\
23\end{array}$ \\
\hline$A Y$ & 0 & 1 & 0 & 6 & 22 & 15 \\
\hline $08 / 09$ & & & & & & \\
\hline
\end{tabular}

As can be seen in 2007/08 the vast majority of PD students scored the LLB students advice letter highly this may have been because as the PD students knew that their marks were going to 'count', albeit only for 5\% they may have been reluctant to 'penalise' the LLB students. However, the comments generally reflected these higher marks.

Similarly the comments of those few students that gave low marks were indicative of the issues which resulted in the lower marks:

- "From viewing the myBU discussion forum it is clear that communication between the IP students was evident, however, they were not successful in effectively communicating with the PD students";

- "Several meetings arranged but not enough in advance to be able to attend";

- "In the end I do believe my questions did get answered but there were a few teething 
problems";

- "Very little advice was given about my own product" (Humphries-Smith, 2009).

Comparing this to 2008/09, there was only one student who was unhappy with his IPP team. He wrote that the advice letter was "well-presented and easy to read". "The letter talks about all relevant issues in IP but does not relate them to my product." "Questions were always answered quickly and thoroughly both in person and online." However, the dissatisfaction arose in the final report: "My report refers to a 'Hoover design' not a bike trailer which is what I designed. At any rate, a Hoover is a brand of vacuum cleaner nothing in report relates to my project."

For the PD students IP is taking seriously and this learning and teaching experience raised a number of issues, particularly related to confidentially, for these students. This is, perhaps, evidenced by the number of questions received, by the Final Year Project Manager for the PD students, prior to the learning and teaching experience commencing. To ensure all parties take the work seriously and act professionally Non-Disclosure Agreements (NDAs) have to be signed by all students, both PD and LLB before any information is exchanged, this normally takes place prior to the first Masterclass and is used as an 'icebreaker' event to introduce the two sets of students.

\subsection{Extracts from Discussion Forums}

A typical email trail from academic year 06/07 can be found in the work of Roach and Soetendorp thus, the results presented here are from academic years 07/08 and 08/09 when the discussions were captured via the myBU based virtual discussion forum.

Below are extracts from the communications of different groups, these are representative of the kind of discussions that this learning and teaching method encouraged.

From our previous meeting/mobile phone messages, I know that for your presentation you were attempting to think of a company name to accompany your product. If this name is distinctive it would be possible to register this as a trade mark, which I will be advising you to do in our advice letter to you. This will both enable consumers to identify the products origin and will allow you to seek remedies for possible infringement. If you are having difficulty with a company name, it is possible to register an individuals name as a trade mark. (Humphries-Smith, 2009)

As can be seen this is the kind of professional advice that would be expected to be obtained from a lawyer. A further example of how myBU was used for recording information discussed at a meeting such as would be undertaken by a practicing lawyer, can be seen below.

A Final meeting with the Design students was held to query a few issues that had arisen as a result of our research and to obtain final copies of the product designs for our use in devising their advice letters. At the meeting I showed the DEC students a copy of the draft advice letter and explained the content of the headings. I also went through the research that has already been undertaken by ?? and I and showed the design students some examples of related existing products and marks that are currently registered as protected.

At the meeting both A and D showed me copies of their final design drawings, I asked both of them to upload electronic copies of these drawings to the community page for our 
use in devising our advice letters. After the meeting I contacted D and A to ask that they title the drawings with a number to aid our reference to them in our letters to them.

A also confirmed at the meeting that her product would be called XXX, and would use a...... D stated that he will be naming his product YYY and that his product would be.....

It was then agreed that we would meet again once the letter had been completed to explain its contents with the DEC students and to answer any further queries the students may still have.

Earlier exchanges tended to be information seeking communications and indicate how the LLB students are attempting to understand the requirements of the PD students. It is fair to say that generally the information was sought by the LLB students rather than the PD students however, it is apparent in some exchanges that both parties are unclear as to what information is needed to be exchanged.

\subsection{Evaluation of Student Feedback}

During the 2008/09 cycle a questionnaire was given to both LLB and PD students at the end of the learning experience in order to obtain qualitative feedback on the experience from the student perspective.

\section{PD}

In response to question 1a) - "Learning to arrange the meetings and what product details the IP industry would need to know..." and "working in groups always beneficial. Using combined knowledge and experience lead to good outcomes."

In response to question 1b) - "Good practice for real life situation."; "experience of working with others." and "interacting in a professional manner was beneficial, although became hard once to we got to know the other students" were common responses. An interesting comment was "It made me think about my product differently and gained a better understanding of my product in the real world."

In response to question 4 - "myBU was useful in order to display results and findings and to set up meetings. Meetings were more useful to have a more detailed, personal discussion ..."; "A little more detail on what the law students were hoping to achieve would have been helpful ie details of the assignment." and "Text messages became as an effective communication tool further to myBU as this became ineffective..." The need to have meetings was a very common comment, there were very few responses that indicated myBU could be used for everything nor that it could it replace face to face meetings to obtain real understanding.

A common response to question 5 was that not everybody turned up to meetings; this was often considered to be as a result of not checking myBU regularly to know when the meetings were being held.

In response to question 6 - "Was good, initial meeting/lecture was useful and the guest lecturers were interesting." and "We had an introduction, which was good, but maybe a follow-up lecture explaining more in-depth about the task." Similar comments regarding needing more guidance were common responses.

In response to question 7 - a number of respondents felt that while the experience was good they would have learnt more on individually, such as "feel I learn more as an individual."

In summary the:

- Academic benefits were considered to be that more was learnt due to more people to do work and different expertise, however, this was only really beneficial when face-to-face discussion 
took place not just communication via myBU.

- In terms of social benefits, the majority of respondents valued the opportunity to meet other students from other backgrounds they would not normally come into contact with.

- The preparation given via the Masterclass was generally considered good but a number of respondents felt that more or an interim lecture on IP would be beneficial.

- myBU was not entirely well received and other methods were used. Communication was generally an issue, particularly people not turning up to meetings or responding to new 'posts', due to it not being obvious on myBU when a new post was available.

\section{LLB}

Most of the LLB students responded to question 1a by noting that they were confronted with different points of view and different aspects of the exercise. They enjoyed exchanging ideas and learning techniques. They also felt that they were getting real experience in applying the law. As for the social benefits of question $1 \mathrm{~b}$, most students enjoyed meeting students from another discipline.

In response to question 4 regarding planning and completing the task, many groups divided the areas of law between themselves, then put the entire letter together latter. This caused some admitted awkwardness due to the different styles of writing. They also felt that the meetings with the PD students were helpful, but wished that myBU was checked more often by everyone. MyBU was not seen as an easy tool to use. Other communication tools, such as texting and emailing, overtook its use.

A similar complaint regarding attendance at meetings was noted by the LLB students. They felt that some of the PD students were not motivated and thus not responsive. This frustrated many LLB students who felt that this lack of participation would reflect in the grade the PD students would give them.

Question 6 - "The IP Masterclass was quite helpful however I think a little more guidance on specific requirements would have been helpful. I felt a little confused as to how academic the answer should be. Also we got the impression that the PD students didn't know what the point of the exercise was." Similar responses for more guidance were made.

In summary:

- Although most students admitted that there was some academic benefit, they tended not to feel that they learned more from the group activity as opposed to working on their own.

- The social benefits were also 50-50 depending as to whether they connected with other students.

- The students generally enjoyed the Masterclass but indicated that another one would have been beneficial.

- The LLB students eventually used myBU as a time and note record as opposed to a communication tool. 


\section{Comparison}

As can be seen in the summaries above:

- Both sets of students found difficulties with using myBU for communication and tend to blame each other for non-attendance at meetings. There is also an element whereby the LLB students found it difficult to know what they needed to ask, and the PD students did not know what the LLB students needed to know.

- The LLB students indicated less satisfaction with working in groups than PD students. On reflection this appears to be less to do with working in the clinical education method than with difficulties the LLB students experienced working collaboratively, as opposed to cooperatively with each other to produce the advice letter;

- Both students found the expectations of collaborative learning challenging and both request greater guidance and input from academic staff rather than exploring the situation for themselves.

\section{CONCLUSIONS}

As a project that has been run for a number of years, being refined and developed in each cycle of operation it has been possible to build a rich picture of the learning experience and thus, to arrive at a number of conclusions. The learning experience aims to combine the clinical education method with a collaborative learning methodology. In fact there is clear evidence that both collaborative and cooperative learning took place as defined by Stahl, Koschmann, Suthers (2006, p3) who cite Dillenbourg (1999) and Roschelle \& Teasley's (1995) in their definition of the difference between cooperative and collaborative learning

In cooperation, the learning is done by individuals, who then contribute their individual results

and present the collection of individual results as their group product... characterization of collaboration, learning occurs socially as the collaborative construction of knowledge. Of course, individuals are involved in this as members of the group, but the activities that they engage in are not individual-learning activities, but group interactions like negotiation and sharing. The participants do not go off to do things individually, but remain engaged with a shared task that is constructed and maintained by and for the group as such.

Certainly this experience provides a 'real life' experience for both sets of students that bridges the academic/practice divide, namely the purpose of clinical education. The LLB students gain the experience of attempting to seek and understand information outside their normal domain, while the PD students have to grapple with explaining technical ideas to a non-technical audience. Both gain experience what it is like to work with real designers/lawyers who are engaged on real design or law work. The PD students have their awareness raised about IP and gain understanding about the whole range of IP issues and how they relate to the potential to commercialize their products. Both sets of students experience working with a totally different group of students that they would not normally engage with on a professional level nor in most cases in a social capacity. They are also required to grapple with determining what information needs to be exchanged.

The introduction of assessment elements for both sets of students has improved engagement and has ensured a more equal collaborative environment is encouraged and has also focused the PD students on this important but relatively small element of their final year project. The LLB students have indicated that they would also like to evaluate and assess the PD students. 
The advantages of this pedagogical approach are many fold. It is clearly student centred with minimal intervention from academic staff thus it requires the students to collaborate to enable success of either party, thus, requiring an immediate sense of ownership - they are in charge of the experience, it is not 'being done to/for them'. It demands that both parties take a level of responsibility and a professional approach to exchange of information and time planning. Theoretically this explorative approach should ensure deep learning is facilitated, however, evaluation of student feedback would suggest that deep learning only happened when discussion took place not just exchange of information, this would be consistent with the definitions discussed regarding collaborative learning.

The introduction of the virtual learning space has had the benefit of formalizing the communication and also allowing capture for analysis purposes. However, myBU was not the best vehicle for communication because it tends to encourage information exchange rather than discussion. Thus the use of a discussion forum would seem to have facilitated cooperative learning and is the likely cause of those students, particularly LLB students, who commented that they would have learnt more individually. Whereas those students who engaged in collaborative learning experienced deep learning which they associated with face to face discussion as this encourages more than just information exchange. However, it is likely that they were engaging collaboratively through the computer mediated communications as well.

\section{FURTHER DEVELOPMENTS}

The project will be operated again for academic year 2009/10, however, as a result of the evaluation reported in this paper the following developments are being considered:

- The addition of an interim masterclass mid-way through the duration of the learning experience, whereby the first masterclass will have the aim of enthusing and motivating and the second masterclass the aim to provide real-life experiences of IP issues by practising designers and how they have exploited IP for commercial purposes;

- Changing the use of myBU to be a record keeping and basic communication method for the LLB students and allowing the students to operate other forms of media for communication such as social networking sites or texting;

- Add a further element to the assessment whereby the LLB students are required to keep a log of their time (phone calls, emails etc) to provide a 'bill' to the PD students. The PD students will in turn have an element of their assessment based on their effective use of their 'lawyer. For example for responding in a timely manner to communications from LLB students.

- This collaborative learning experience is being rolled out to more courses in the design area and also to a new subject area with involvement of a final year students on a course in music and audio technology.

\section{References:}

Allen, V. (2006) A Reflection on Delivering Legal Education to Business Students a paper delivered at Learning in Law Initiatives, University of Warwick

Booton, D. \& Prime, T. (2001) Intellectual Property as Part of the Undergraduate Law Curriculum: Theory and Practice, Potential and Reality [unpublished] cited in Soetendorp, R. Intellectual

Property Education - In the Law School and Beyond (2005) on file with authors, also available at http://www.engsc.ac.uk/downloads/miniproject/ip/IPintheLawSchoolandBeyond.pdf 
Brayne, H. Duncan, N. \& Grimes, R.(1998) Clinical Legal Education: Active Learning in Your Law School, London: Blackstone

Brooker, S. (2004) Public legal education: comments by the National Consumer Council on the Advice Services Alliance, Citizenship Foundation and Legal Action Group discussion paper on a national strategy for public legal education. London: National Consumer Council

Burridge, R. et al (2002) Effective learning and teaching in law. London: Routledge

Cownie, F. (2004) Legal Academics London: Hart

Engineering Council UK, 2008. UK-SPEC. Available at http://www.engc.org.uk/ukspec/default.aspx accessed 12th January 2009

Gower, A. (2006) Gowers Review of Intellectual Property. Available from http://www.hmtreasury.gov.uk/gowers_review_index.htm accessed 30th January 2009

Hennessey, W. (1999) The place of intellectual property teaching in the curricula of universities and technical institutes. online paper, Concord, NH: Franklin Pierce Law Center

Humphries-Smith, T. (2009) Collaborative Student Centred Learning-Intellectual Property for Product Designers, Design Education: Creating a Better World, Proceedings of $11^{\text {th }}$ Engineering and Product Design Education International Conference, Brighton University, UK.

McQuoid-Mason, D. (2006) Using your imagination to light up knowledge, skills and values for LLB students: clinical legal education and effective lessons a paper delivered at Learning in Law Initiatives, University of Warwick

Outram, G., Stevens, C. and Culley, S. (September 2007) Extended Group Design Activities for the Enterprise Society at $9^{\text {th }}$ International Conference on Engineering \& Product Design Education, EPDE07, Northumbria University, Newcastle-upon-Tyne, Basildon, Essex: Hadleys Ltd.

Pitkethly, R. UK Intellectual Property Awareness Survey, 2006, London, UK. Available at: www.ipo.gov.uk/ipsurvey.pdf accessed 3rd February 2009

Race, P. (2005) Making Learning Happen: A Guide for Post-Compulsory Education, London: Sage Publications Ltd.

Roach, J. and Soetendorp, R. (2008) Report - Intellectual property in the engineering syllabus - a model for integrating key but not core concepts across the disciplines, The Higher Education Academy - Engineering Subject Centre, Loughborough

Schiavetta, S. (2001) 'Computer Games Technology and Legal Education and Its Impact on Legal Systems', 16 ${ }^{\text {th }}$ BILETA Annual Conference, University of Edinburgh, Scotland

Soetendorp, R. (2004) 'Food for engineers': intellectual property education for innovators, 
Soetendorp, R. (2006) Intellectual property for engineers: a curriculum development project a paper delivered at Learning in Law Initiatives, University of Warwick

Stahl, G., Koschmann, T., Suthers,D. (2006) Computer-supported collaborative learning: an historical perspective in Cambridge handbook of the learning sciences, Ed. Sawyer, R. Cambridge University Press.

Wood, B. and Duffy, M. (September 2008) "Developing Design Graduates as Entrepreneurs" at 10 th International Conference on Engineering \& Product Design Education, EPDE08, Universitat Politecnica de Catalunya, Barcelona, Barcelona: Artyplan Global Printer Ltd. 